\title{
Timing the greening of the land
}

\author{
YongBo Peng ${ }^{1,2}$, Huiming BAO ${ }^{1,2,3}$, CHENGGUO \\ GUAN $^{3}$, SHANGGUI GONG ${ }^{3}$, KALLE KIRSIMÄE ${ }^{4}$, ZIRAN \\ $\mathrm{WEI}^{3}$, PEETER SOMELAR ${ }^{4}$ \\ ${ }^{1}$ International Center for Isotope Effects Research, Nanjing \\ University, Nanjing 210023, China \\ ${ }^{2}$ School of Earth Sciences and Engineering, Nanjing \\ University, Nanjing 210023, China. \\ ${ }^{3}$ Department of Geology and Geophysics, Louisiana State \\ University, Baton Rouge, LA 70803, USA \\ ${ }^{4}$ Department of Geology, Tartu University, 50411 Tartu, \\ Estonia.
}

It is generally accepted that life on Earth started from the ocean and later moved on to the land. The invasion of the land is the most transformative endeavor that life on the planet Earth has ever undertaken in its more than 3.5 billion year's history. A high-resolution temporal record is thus of great importance to understanding this crucial event in biological evolution on this planet. Molecular clock suggests that the onset of land colonization may have begun at as early as ca. 600 million years ago (Ma), however, the exacting timing of an established biosphere on land has been elusive, due largely to the lack of either fossil or chemical evidence in land deposits.

Biologically processed $\mathrm{PO}_{4}$ will have typically much higher $\delta^{18} \mathrm{O}$ values ( $15-24 \%$, VSMOW) than the ones inherited from igneous sources (ca. 6\%o), resuling from $\mathrm{PO}_{4}^{3-}$ exchanges oxygen with that of ambient water during biological activities. Therefore, an increase in the $\delta^{18} \mathrm{OPO}_{\mathrm{PO}}$ from pristine igneous rocks to the upper more weathered ones should be expected if there was once active soil biological P-cycling.

We developed a new method to extract trace phosphate from igneous weathering profile and have examined drill core samples from weathering profiles on basalts of modern, Permian, Cambrian, and Neoproterzoic ages. The data show that the $\delta^{18} \mathrm{OPO}_{\mathrm{PO}}$ for all analyzed weathered profiles are $8-24 \%$ higher than those in un-weathered, underlying parent igneous rocks, suggesting that biologically mediated weathering on land has been extensive since as early as Neoproterzoic Era. These is concrete evidence in supporting of a widespread greening of the land in late Neoproterozoic. We are currently examining older paleo-weathering profiles to extend the landing history of life on our planet. 